\title{
Simpósios Regionais de Atividade Física e Saúde
}

Rev Bras Ativ Fis Saúde p. 399-399

$\mathrm{DOI}$

http://dx.doi.org/10.12820/rbafs.v.19n3p399

Rodrigo Siqueira Reis ${ }^{1}$

Mathias Roberto Loch ${ }^{1}$

Cassiano Ricardo Rech

1 Sociedade Brasileira de Atividade Física e Saúde (SBAFS) - Gestão 2014-2015.

Entre os desafios a serem enfrentados para o avanço da nossa área temos destacado a necessidade de aumentar a capilaridade da Sociedade Brasileira de Atividade Física e Saúde (SBAFS) o que não é uma tarefa simples para um país como o nosso, continental, desigual e plural. Ao completar os primeiros seis meses à frente da SBAFS, gostaríamos de celebrar um enorme avanço com a confirmação de cinco Simpósios Regionais de Atividade Física e Saúde.

Pela primeira vez teremos eventos alcançando todas as regiões do Brasil, seguindo o já tradicional Simpósio Nordestino (que este ano terá sua XII edição), todas as outras regiões realizarão seu primeiro simpósio regional de Atividade Física e Saúde. Isso só será possível em função do esforço de destacados pesquisadores. No Sul o Professor Gabriel Gustavo Bergman (Uruguaiana, RS), no Sudeste o Professor Eduardo Kokobun e a Professora Priscila Missaki Nakamura (Rio Claro, SP), no Centro-Oeste a professora Christianne de Faria Coelho (Cuiabá, MT), no Nordeste o professor Bráulio Mendonça (Maceió, AL) e no Norte a professora Marceli Pureza de Melo (Macapá, AP) que com suas respectivas equipes de apoio e demais colaboradores estão fazendo história.

Este não é um feito pequeno. Como todos devem imaginar, foram muitos os desafios e dificuldades, mas prontamente enfrentadas e superados com competência, dedicação e abnegação de colegas das cinco regiões. Sem dúvida veremos os frutos destes eventos e iniciativas sendo colhidos em breve e que seja um ótimo aperitivo para o X CBAFS na cidade de São Luiz, MA no próximo ano.

Esperamos que estes eventos contribuam para uma maior aproximação da SBAFS com os diversos atores da Atividade Física e Saúde do Brasil. Agradecemos a todos os colegas envolvidos na organização dos eventos e celebramos com toda a nossa comunidade este importante avanço para a área. 